\title{
PERANCANGAN SITUS WEB KUSTOMISASI BENGKEL VIRTUAL DEUS EX MACHINA
}

\author{
${ }^{1}$ Sahid Maulana, ${ }^{2}$ Paku Kusuma \\ Universitas Telkom, Program Studi Desain Komunikasi Visual \\ Jl. Telekomunikasi No. 1, Dayeuh Kolot, Jawa Barat \\ ${ }^{1}$ sahidmaulana@gmail.com, ${ }^{2}$ does.sense@gmail.com
}

\begin{abstract}
ABSTRAK
Tren sepeda motor kustom yang berkembang dikalangan anak muda akhir-akhir ini, tidak lepas dari pengaruh internet sebagai media komunikasi dan informasi. Salah satu pengaruhnya berasal dari sebuah lini dengan nama Deus Ex Machina yang bergerak dibidang kustomisasi sepeda motor. Mereka secara aktif menggunakan internet dan media sosial sebagai media utama dalam berkomunikasi serta promosi. Perancangan sebuah sepeda motor kustom memerlukan waktu dan biaya yang tidak sedikit. Oleh karena itu diperlukan sebuah media komunikasi berbasis web yang mampu mengkomunikasikan keinginan pengguna dengan kemampuan builder sepeda motor kustom agar lebih efektif dan efisien. Web aplikasi adalah media yang tepat untuk permasalahan ini, dengan internet sebagai media, dan penjelajah web sebagai jendela. Perancangan web aplikasi ini diharapkan dapat menjadi solusi bagi kedua belah pihak dalam merancang sepeda motor kustom yang memuaskan dalam kerjasama yang terjalin.
\end{abstract}

Kata Kunci: sepeda motor kustom, kustomisasi, web aplikasi, media sosial.

\begin{abstract}
Customized motorcycle trend spreading among youth recently cannot be separated from the emergence of internet as communication and information media. One of the influences comes from Deus Ex Machine line that runs customization on motorcycle. They actively use internet and social media as the main media in communication and promotion. The designing process on a customized motorcycle takes time and a high cost. Therefore, a web based communication medium that can communicate users' needs to the builder's ability is required so that the process is more effective and efficient. Web application is a medium appropriate for the problem. By using internet as the medium and web explorer as the window, this web application design is expected to be the solution for both parties in designing customized motorcycle.
\end{abstract}

Keywords: Customized motorcycle, Customization, Web Application, Social media. 


\section{PENDAHULUAN}

Tren sepeda motor kustom yang mewabah akhir-akhir ini dikalangan anak muda di berbagai daerah, tidak lepas dari peran internet sebagai media informasi dan komunikasi. Internet layaknya jaringan hidup yang telah banyak mempengaruhi kehidupan manusia dalam berbagai aspek, baik sosial, ekonomi, politik, maupun kebudayaan. Berbagai lapisan tatanan seperti terbentuk ulang dengan kehadiran internet, termasuk pola dan gaya hidup. Hal ini pula yang menjadikan acuan dalam pembentukan trend, termasuk moda transportasi sepeda motor kustom. Sepeda motor kustom sebenarnya adalah sebuah istilah yang dipakai untuk menandakan sebuah aliran sepeda motor tertentu. Di Indonesia, aliran sepeda motor kustom meliputi aliran Japs-style, Cafe-racer, Dirttracker, Flat-tracker, Scrambler, Bobber, dan lainnya.

Aliran sepeda motor kustom sebenarnya bukanlah hal baru, jenis-jenis sepeda motor kustom berkembang di tahun 60-70an di beberapa negara seperti Eropa, Amerika, dan Jepang, saat itu istilah custom yang dimaksud berbeda dengan interprestasinya zaman sekarang. Oleh karena itu istilah sepeda motor kustom saat ini, seringkali ditambahkan kata 'vintage' yang berarti 'yang telah lalu', 'kuno', 'ketinggalan zaman' didepan frase custom motorcycle. Layaknya roda yang berputar, tren ini tenggelam dan kemudian timbul kembali saat ini dengan istilah vintage custom motorcycle yang bersifat eklektik.

Sepeda motor, selain fungsi utamanya sebagai alat transportasi, juga menjadi identitas terhadap sebuah sikap dan pemikiran tertentu dari ide yang dianut pengendaranya. Seseorang dapat diketahui latar belakang dan pribadinya dari sepeda motor yang mereka gunakan. Bagi mereka, tren sepeda motor kustom berjalan bersamaan dengan berkembangnya dunia fashion, musik, perkembangan teknologi, dan pergaulan anak muda saat ini. Tren ini telah berkembang menjadi sebuah gaya hidup yang mencerminkan karakter seseorang dalam berkeseharian.

Kustomisasi sepeda motor memiliki pengertian sederhana mengubah bentuk dan fungsi asli produksi pabrikan dari mulai bagian terkecil hingga terbesar ke spesifikasi yang diinginkan si pengendara. Modifikasi yang dilakukan bersifat eksperimen dan coba-coba, tidak sedikit dari mereka yang menemui kegagalan atau rasa kurang puas dengan modifikasi yang sudah dilakukan. Kurangnya pemahaman calon kustomer, terbatasnya kemampuan modifikator, serta penyampaian ide yang meleset selalu menjadi permasalahan yang utama dalam merakit sebuah sepeda motor kustom. Calon kustomer mempunyai banyak kehendak dalam mengkonsep sepeda motor kustomnya yang sesuai dengan keinginan dan pribadi mereka, namun sering kali modifikator salah mengeksekusi.

Deus Ex Machina, sebuah label yang bergerak dibidang kustomisasi sepeda motor, selain memiliki offline store di Bali, mereka pun memasarkan produknya lewat internet. Media internet dewasa ini menjadi sebuah kebutuhan yang tidak terelakan lagi, segala bentuk informasi didapatkan dengan mudah dan murah. Dalam situs resmi Deus Ex Machina terdapat berbagai informasi mengenai produk dan informasi berupa blog mengenai brand dan kegiatan yang sedang dilakukan, pelanggan dapat pula melakukan pembelian produk secara online, tetapi untuk produk sepeda motor baru 
sebatas katalog saja. Perihal lengkap lain mengenai pembelian, perancangan, dan perakitan hanya dapat dilakukan langsung di bengkel.

Dengan berkembangnya teknologi internet, perangkat lunak, dan perilaku pengguna internet yang terus berkembang, dibutuhkan sebuah media komunikasi yang dapat mempertemukan bengkel kustomisasi sepeda motor dengan calon pelanggan dalam bentuk perancangan virtual berbasis situs web.

\section{URAIAN PENELITIAN}

\subsection{Teknik Pengumpulan Data}

Dalam melakukan perancangan situs web aplikasi sepeda motor maya Deus Ex Machina ini, data dikumpulkan melalui studi literatur/sejarah, wawancara dan survey lapangan terkait beberapa praktisi yang terkait dengan topik perancangan aplikasi ini. Studi literatur dilakukan untuk memperdalam topik yang dipilih dalam latar belakang, memperjelas batasan masalah, membatasi fokus perancangan, dan tujuan yang ingin dicapai dari perancangan situs web aplikasi.

Wawancara dilakukan secara langsung dengan modifikator sepeda motor kustom karena pengumpulan informasi yang dibutuhkan sebagian besar berbicara soal masalah teknis dalam membangun sebuah sepeda motor. Dari wawancara ini akan diperoleh data yang akurat mengenai karakteristik konsumen, sehingga perancangan akan lebih tepat sasaran. Survey lapangan dilakukan untuk memperoleh data yang berupa langkahlangkah menyusun sepeda motor serta data foto seluruh bagian dari sepeda motor kustom. Data foto ini kemudian diolah menjadi data visual berupa ikon yang nantinya digunakan sebagai representasi dari tiap-tiap bagian sepeda motor.

Survey perlu dilakukan untuk mengetahui sejauh mana target pasar ingin memiliki sepeda motor dengan label Deus Ex Machina. Selain itu adakah hal lain yang menjadi daya tarik seseorang memilih label Deus Ex Machina sebagai builder sepeda motor mereka.

\subsection{Proses Analisis Data}

Data literatur dan data lapangan dijabarkan untuk diambil titik utama seperti bagian sepeda motor manakah yang diperbolehkan dimodifikasi dalam perancangan sepeda motor custom. Hal ini digunakan sebagai kunci dan landasan dalam perancangan aset desain web aplikasi.

\subsection{Proses Perancangan Web Aplikasi}

Perancangan situs web diawali dengan menentukan skenario aplikasi, aturan bermain, fitur, dan tampilan muka. Mood board dirancang sesuai dengan brand image label. Pada proses ini akan ditentukan visual style dan skema warna yang digunakan dalam aplikasi.

Desain interface aplikasi mulai dirancang sesuai dengan data yang diperoleh dari wawancara dan survey terhadap target pasar. Elemen visual yang digunakan disesuaikan dengan image label deus ex machina.

Situs we aplikasi yang dirancang akan diintegrasikan dengan Situs resmi deus ex machina, pada menu "Motorcycle" tepatnya hyperlink "Custom Order Available" aplikasi 
akan mulai running. Setelah selesai mengkustom, pengguna dapat membagikan karya mereka di media sosial facebook, twitter, tumblr, dan lainnya.

\section{OBJEK KAJIAN}

Secara umum, perancangan ini akan bertitik pada penyempurnaan atau peluasan fitur yang ditawarkan Deus Ex Machina melalui media web dengan perancangan simulasi bengkel digital pada web aplikasi. Pengolahan aset akan dirancang presisi dan akurat sesuai dengan material sebenarnya, diolah dengan gaya visual yang bersifat datar dan ikonik. Tampilan pengguna (user interface) dirancang sederhana agar pengguna lebih mudah mengoperasikan aplikasi. Pilihan komponen yang beragam dan fitur-fitur khusus membuat kustomer bebas berkreasi sehingga karya yang dibuat pengguna lebih bersifat personal.

Disamping itu, fitur lain yang sama pentingnya adalah fitur social media sharing. Media sosial menjadi sebuah tempat bagi netizen (pengguna internet) dalam berinteraksi dan berinteraksi sosial. Saat ini terdapat banyak media sosial yang populer, dalam perancangan ini media sosial yang dipilih adalah facebook, twitter, instagram. Dalam perancangan ini situs aplikasi dapat digunakan sebagai acuan atau referensi visual dalam merancang sepeda motor kustom yang dapat dibuat bengkel Deus Ex Machina, namun tetap diperlukan konfigurasi pada eksekusi yang sebenarnya.

Setiap sepeda motor yang telah selesai dirancang, akan dishare pada media sosial yang dipilih pengguna, sebagai contoh, media yang digunakan adalah Facebook, Semua daftar teman yang tehubung dengan akun perancang dapat melihat status update yang berupa photo sharing dari aplikasi ini.
Media sosial sering kali menghasilkan efek domino terhadap suatu peristiwa yang sedang ramai diperbincangkan di dunia nyata, ataupun didunia maya itu sendiri. Respon terhadap sebuah peristiwa, pernyataan, pendapat, bahkan sebuah foto, dapat memberikan reaksi spontan yang cukup 'vulgar'. Maksudnya adalah media sosial memberikan keberanian lebih dari persepsi atas pernyataan status, pendapat, ataupun sebuah berita yang tersebar di media sosial. Hal ini disebabkan oleh penerjemahan bahasa tulisan yang berbeda pada setiap orang. Hilangnya intonasi dan nada dalam berbicara, menjadi salah satu penyebabnya.

Kaitannya dengan perancangan web aplikasi ini adalah bagaimana karakter fitur share pada media sosial dan karakter pengguna, dapat mempengaruhi pengguna lain untuk melihat dan mencoba aplikasi ini. Bahasa visual pada image akhir perancangan, haruslah bersifat persuasif namun dengan cara halus, artinya rancangan final yang dishare memiliki muatan iklan namun tersembunyi. Web aplikasi ini mengajak pengguna secara paralel digiring untuk diperkenalkan dengan label Deus Ex Machina.

Dengan terlebih dulu meninjau label Deus Ex Machina dari segi produk yang diproduksi, deus ex machina memiliki 3 kata kunci sebagai berikut : sepeda motor kustom; olah raga surfing; gaya hidup. Ketiga kata ini adalah kata kunci utama, kemudian sub kata kunci yang melekat seperti dunia seni rupa, musik, dan fesyen yang memperluas serta merangkum label ini secara keseluruhan. Konsep desain yang digunakan lebih mengarah kepada emotional branding. Deus Ex Machina tidak secara eksplisit mempersuasi kustomernya untuk memakai produk mereka, tetapi 
menampilkan sisi kehidupan sehari-hari yang bersifat apa adanya dari kultur yang mereka lakoni, sepeda motor dan surfing, freedom rider.

Gaya gambar tangan bebas (free hand drawing) merupakan salah satu unsur yang melekat pada label ini, dibuat oleh beberapa seniman lepas yang berkarya dan berpameran disana lalu berkolaborasi dengan desainer grafis label ini menghasilkan karya visual yang bersifat ikonik dan kontemporer, melebur antara ranah seni dan desain grafis masa kini. Citra visual seperti ini menjadi identitas khas mereka yang dilihat dari sudut pandang branding, terbangun sangat kuat. Setiap dokumentasi foto dan video yang disuguhkan kepada target pasar lewat media sosial tidak bersifat persuasif namun lebih kepada penceritaan keseharian dan apa adanya, menggambarkan kebebasan dalam menikmati hidup, yang pada dasarnya diimpikan oleh semua orang. Perasaan iri inilah yang kemudian secara tidak langsung menarik pasar untuk lebih mengenal label ini.

Proses perancangan visual melibatkan dua unsur yaitu desain grafis dan scripting atau pemrograman bahasa maya. Dengan berkembangnya HTML5, CSS3, JavaScript dan bahasa pemrograman lainnya memberikan keleluasaan kepada desainer grafis, untuk mengonsep aplikasi sesuai dengan target yang ingin dicapai, tidak terbatas pada kemampuan software atau hardware yang digunakan.

\section{LANDASAN TEORI}

Gaya visual yang bersifat flat dan sketsa tangan, merupakan gaya visual yang sering digunakan oleh label Deus Ex Machina dalam mengolah grafis pada media cetak dan elektronik. Gaya seperti ini juga mengacu pada gaya flat user interface (Flat UI) atau tampilan muka datar, yang akhir-akhir ini cukup populer, terlebih lagi pada tampilan muka aplikasi dan perangkat lunak.

\subsection{Aset-aset.}

Aset pada web aplikasi ini meliputi semua sepeda motor dan parts yang digunakan Deus Ex Machina dalam membangun sepeda motor kustom pelanggan mereka. Setiap parts akan dimodelkan berdasarkan materi foto yang diambil sewaktu proses perakitan, kemudian akan proses di 'digitalkan' dan disederhanakan bentuknya mendekati bentuk dan sifat sebuah ikon. Ikon-ikon ini merepresentasikan bentuk asli dari setiap parts. Adapun parts-parts tersebut adalah: rangka, mesin, velg, tromol, ban, peredam kejut (depan-belakang), swing-arm, lampulampu, jok, tanki bahan bakar, handle grip, stang, spatbor, spion dan detail lainnya.

Perancangan akan difokuskan kepada jenis sepeda motor Yamaha Scorpio 225cc. Aset diolah dengan memisahkan parts, dengan menggambar ulang setiap parts pada layer yang berbeda. Setelah digambar ulang, aset kemudian diolah lagi dari gambar garis ke bentuk datar.

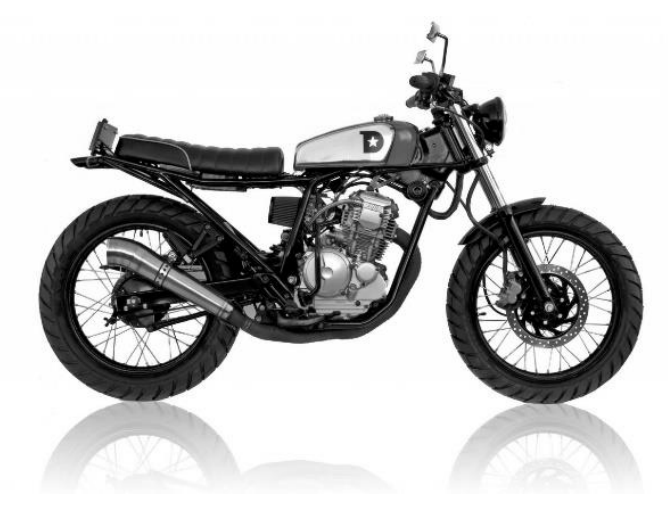

Gambar 1. Anatomi Sepeda Motor-Foto asli sepeda motor yang digunakan dalam membuat aset parts.

(Maulana, 2014) 

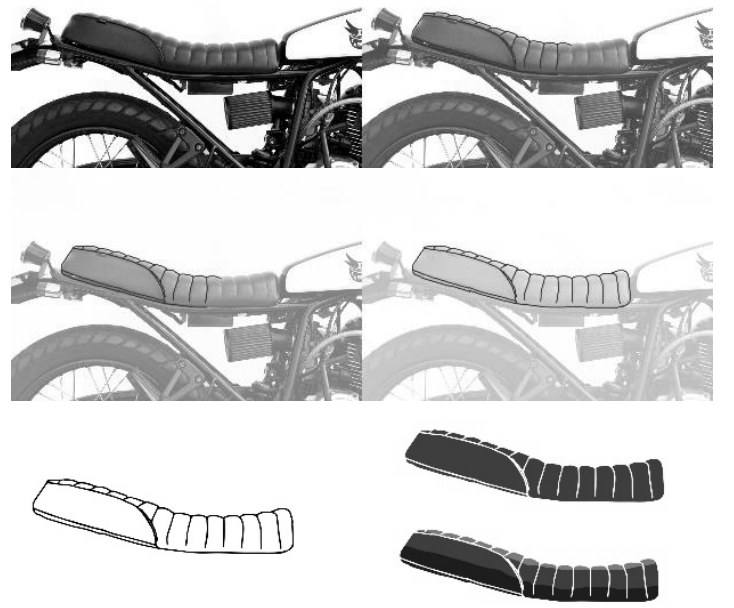

Gambar 2. Proses pembuatan aset parts dari foto. Sumber : (Maulana, 2014)

\subsubsection{Frame-engine, air box}

Perancangan ini, digunakan 3 rangka kustom dan 1 rangka dasar yamaha scorpio 225. 3 Rangka kustom ini, terdiri dari 1 rangka dasar jenis sepeda motor cafe racer, dan dua jenis rangka dasar flat-tracker. Perbedaan ke empat rangka ini adalah pada bagian belakang dari tulang utama motor. Tulang utama adalah batang logam besar penyangga mesin. Bentuknya bisa lebih panjang dan menyudut, dapat pula pendek lurus, ataupun gabungan dari keduanya. Air box adalah bagian berbentuk segitiga dibagian bawah jok, tulang rangka utama dan tulang penyangga rangka. Biasanya berbahan dasar plastik ataupun logam yang berfungsi untuk melindungi akumulator dan filter udara karburator.
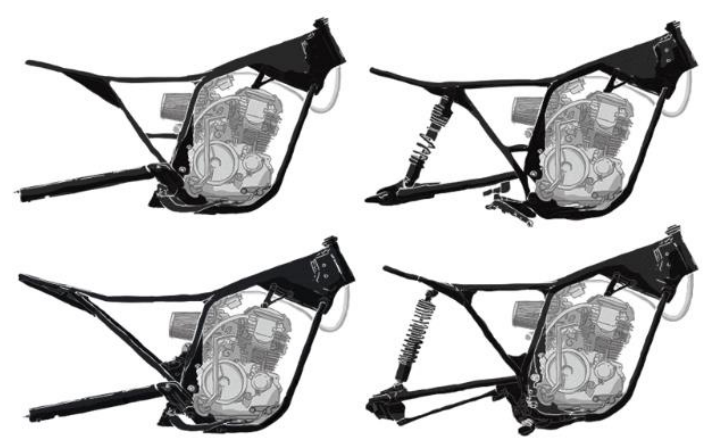

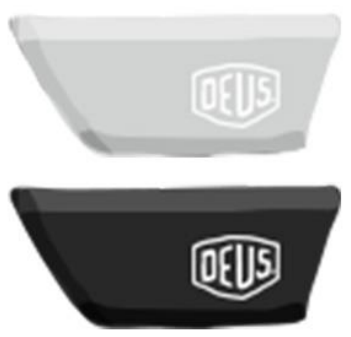

Gambar 3. Rangka dasar dan kotak udara. Sumber : (Maulana, 2014)

\subsubsection{Knalpot}

Terdapat 6 model alternatif knalpot yang bisa digunakan dalam kustomisasi Yamaha Scorpio 225 ini, dimulai dari bentuk knalpot leher pendek lurus sampai panjang bersudut, besar diameter knalpotnya pun cukup variatif. Selain bentuk terdapat dua alternative pilihan warna yang disesuaikan yaitu: abu natural atau chrome dan hitam.

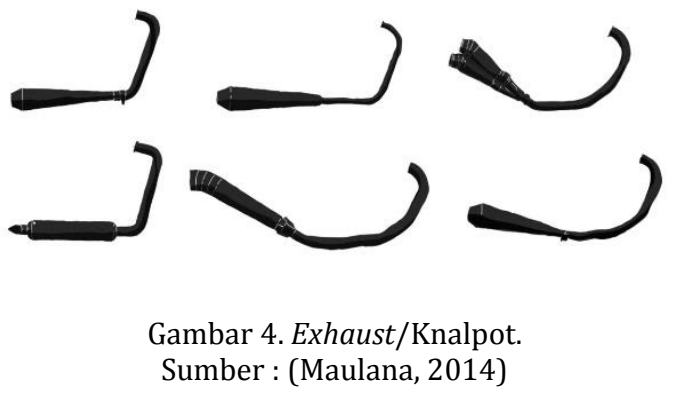

\subsubsection{Peredam Kejut Depan}

Secara garis besar, peredam kejut depan difungsikan sebagai kekuatan dan kestabilan pengendara motor. Peredam ini hanya memiliki perbedaan kecil pada setiap preferensinya, yaitu di posisi stang. Ada 3 opsi posisi, posisi bawah biasanya untuk jenis sepeda motor cafe-racer, tengah dan atas untuk jenis flat-tracker. Posisi pengendali ini (stang) nantinya akan juga membentuk gesture dari si pengendara dan berpengaruh pada rangka tulang belakang si pengendara. 


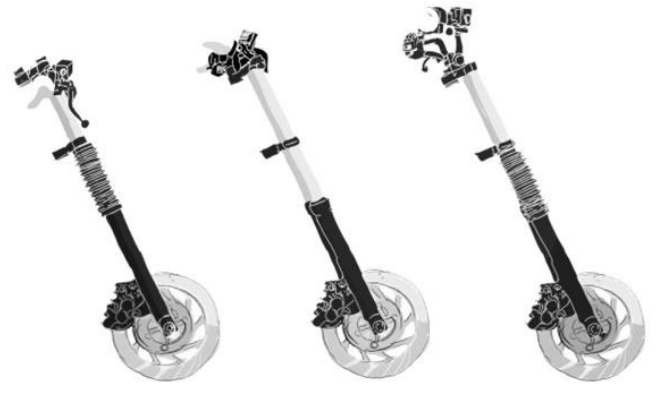

Gambar 5. Peredam kejut depan. Sumber : (Maulana, 2014)

\subsubsection{Handgrip, Lampu Depan}

Handgrip tersedia dalam 1 jenis varian saja dengan 2 warna. Lampu depan terdiri dari dua jenis varian dengan masing-masing terdapat dua pilihan warna. Abu-abu/krom dan hitam.
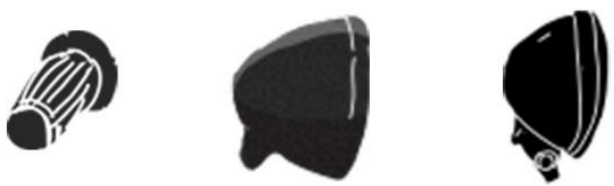

Gambar 6. Handgrip dan Lampu Depan. Sumber : (Maulana, 2014)

\subsubsection{Velg, Ban, Spatbor}

Velg, Ban, dan Spatbor. Untuk velg hanya disediakan 1 jenis velg saja dengan 1 jenis ukuran. Untuk Ban, depan maupun belakang, biasanya digunakan merk dan jenis ban yang sama. Terdapat 4 jenis ban yang dapat dipilih dengan 1 jenis warna saja, yaitu hitam. Spatbor depan dan belakang memiliki masing-masing antara 2-5 varian.

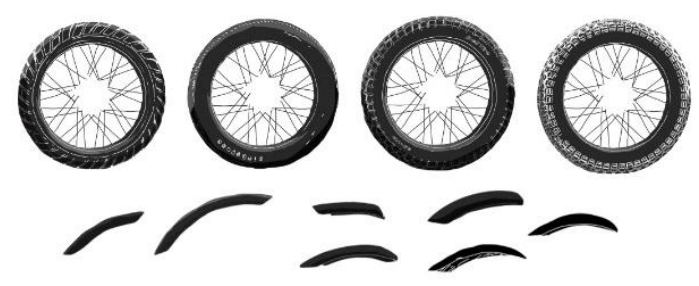

Gambar 7. Ban dan Spatbor. Sumber : (Maulana, 2014)

\subsubsection{Jok}

Jok dibuat sesuai dengan rangka dasar yang dipilih, pada opsi ini terdapat 3 alternatif jok untuk setiap jenis rangka dasar. Warna kulit yang tersedia adalah hitam dan coklat.
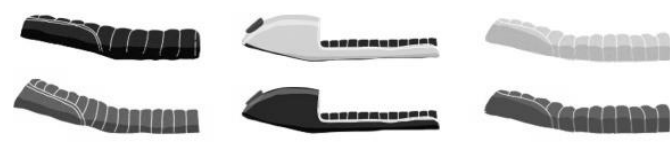

Gambar 2.8 Saddle/Jok. Sumber : (Maulana, 2014)

\section{PEMBAHASAN}

Gaya visual yang bersifat flat dan hasil pengolahan dari sketsa tangan, merupakan gaya visual yang sering digunakan oleh label Deus Ex Machina dalam setiap proyek yang ditanganinya. Hal ini menjadi identitas unik.

\subsection{Logo}

Logo yang digunakan adalah logo merk dagang resmi dari Deus Ex Machina yang diambil dari situs reminya. Logo ini dikomposisikan ulang bersama logo aplikasi yang dibuat dengan mengambil ambience dari stok visual yang telah dimiliki oleh Deus Ex Machina. Stok visual ini sengaja digunakan untuk menjaga benang merah antara brand image yang telah terbentuk, dengan web aplikasi yang dirancang.

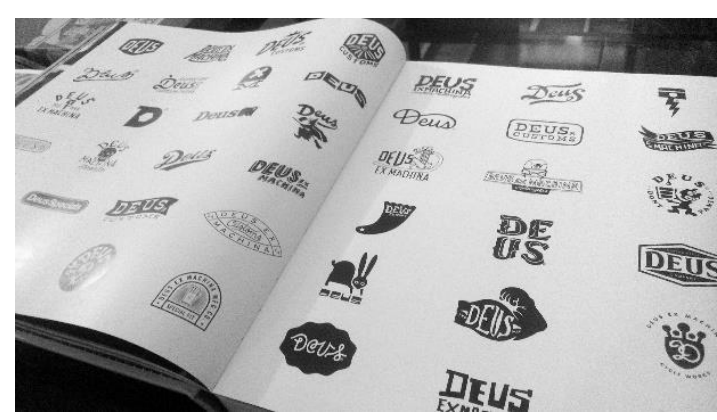

Gambar 8. Kumpulan Visual logo stock Deus Ex Machina. Sumber : (Maulana, 2014) 
BUILOYOUA

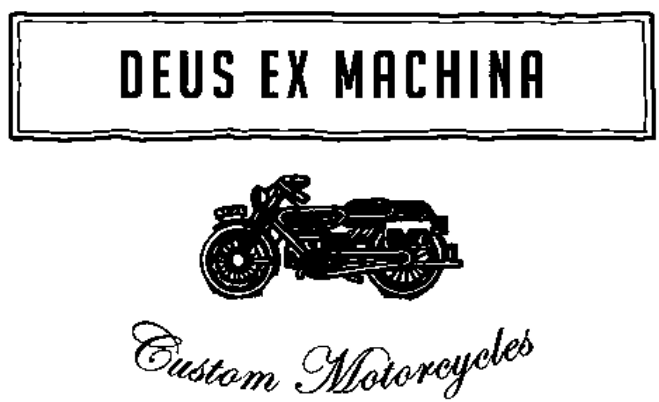

Gambar 9. Logo aplikasi situs Deus Ex Machina. Sumber : (Maulana,2014)

\subsection{Warna}

Secara garis besar, padanan warna yang dipakai dalam situs web nantinya adalah warna-warna maskulin dan elegan.

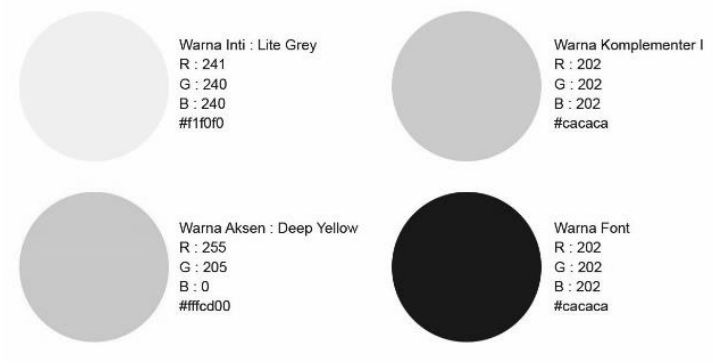

Gambar 10. Palet warna pada situs aplikasi. Sumber : (Maulana, 2014)

Menurut Angela Wright, seorang psikolog di Rumah Sakit Queen Mary's, Roehampton, Inggris, dan di Carmel, California, Amerika Serikat, warna abu-abu memiliki makna yang netral atau warna kompromi. Semakin mendekati hitam semakin misterius dan kelam, semakin mendekati putih semakin terang dan hidup.

Warna kuning, digunakan sebagai aksen dari warna dasar abu-abu. Memiliki arti optimisme, kepercayaan diri, harga diri, kekuatan emosional, keramahan, dan kreativitas. Warna hitam pada dasar abuabu dan kuning membentul warna kontras yang solid. Digunakan sebagai warna pada aksara dan tombol-tombol informasi.

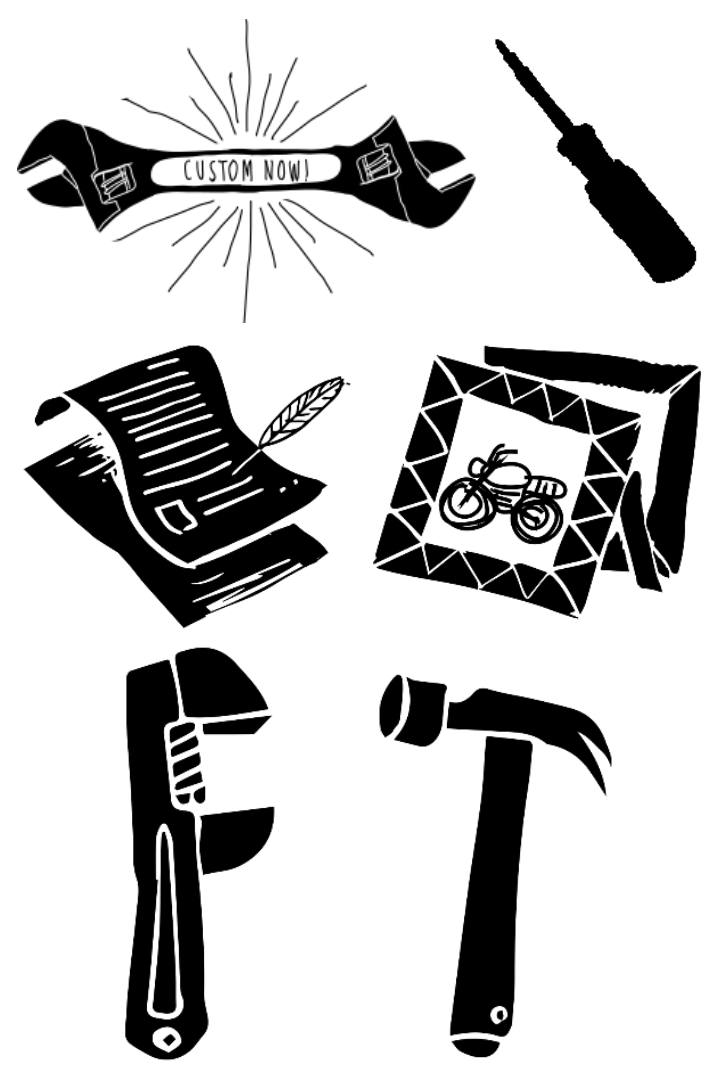

Gambar 11. Tombol, Kursor, dan Tombol Navigasi Situs Web Aplikasi. Sumber : (Maulana, 2014)

\subsection{Rancangan Layout dan Blocking}

\subsubsection{Tampilan Muka Versi Desktop}

Desktop atau Personal Computer memiliki berbagai macam resolusi layar (screen resolution). Hal ini tergantung dari merk dan jenis layar yang digunakan pengguna. Dalam merancang tampilan aplikasi, digunakan resolusi bidang layar 1024x768 pixel. Pemilihan resolusi layar ini dipilih berdasarkan daftar device yang banyak tersedia dan banyak digunakan dipasaran.

Secara garis besar, perancangan situs aplikasi sepeda motor kustom ini terbagi menjadi tiga halaman utama. Halaman pertama dirancang sebuah halaman selamat 
datang (welcome screen) atau landing page. Pada halaman ini terdapat nama situs, logo situs, dan tombol untuk melanjutkan ke halaman berikutnya. Halaman situs memiliki latar berwarna putih dengan efek tekstur pasir dan garis-garis grid.

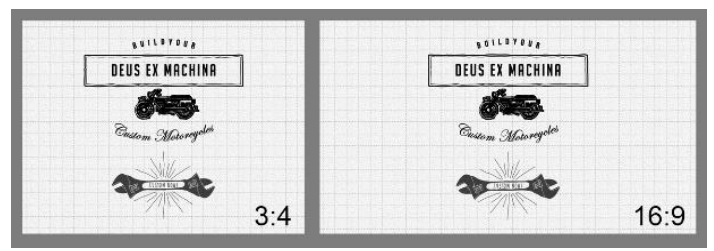

Gambar 12. Rasio layar.

Sumber : (Maulana, 2014)

Garis grid terinspirasi dari kertas milimeter block. Kertas ini banyak digunakan untuk perancangan gambar teknik, maupun gambar desain grafis. Garis vertikal dan horizontal pada kertas ini berfungsi sebagai garis bantu dalam menggambar. Dengan sedikit penyesuaian pada warna dan bentuk, didapatkanlah visual yang diinginkan.

Latar belakang pada tata ruang dibuat dengan teknik seamless background atau repeating pattern. Teknik ini memiliki dua keunggulan, yaitu file gambar tidak perlu dibuat penuh sesuai dengan resolusi layar, melainkan hanya berbentuk modul gambar dengan ukuran kecil. Ukuran gambar yang kecil mengakibatkan ukuran file yang kecil juga, memberikan keuntungan saat pemuatan file dan gambar sewaktu situs aplikasi diakses.

Modul gambar kecil ini nanti akan otomatis memenuhi tata ruang (layout) dengan dibantu kode CSS (Cascading Style Sheet). Perintah tersebut gambar latar belakang akan otomatis diulang menurut sumbu $\mathrm{x}$ dan sumbu $\mathrm{y}$. Desain modul dirancang agar selalu terlihat menyatu dan sama ketika modul tersebut diperbanyak. $\mathrm{html}\{$

color:\#000;

background: url(../img/app/bg.jpg);

font-family: Arial;

font-size:12px;

\}

Gambar 4.2 Perintah CSS untuk seamless background. Sumber : (Maulana, 2014)

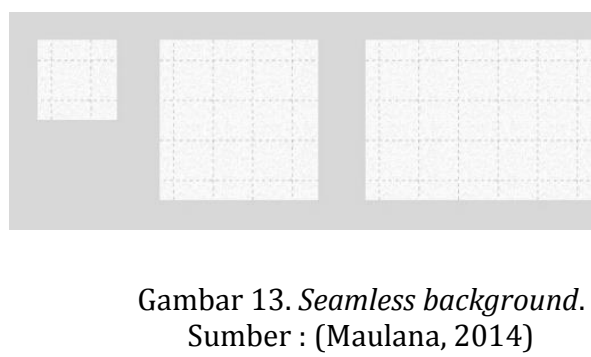

Untuk melanjutkan ke halaman berikutnya pengguna harus mengklik tombol mulai yang ditandai dengan gambar kunci pas mata ganda yang bertuliskan 'custom now'. Setelah diklik barulah pengguna masuk ke halaman berikutnya. Proses ini ditandai dengan sedikit animasi, logo sepeda motor akan berjalan maju kesebelah kiri layar dengan efek suara mesin sepeda motor yang semakin menghilang (fade-out).

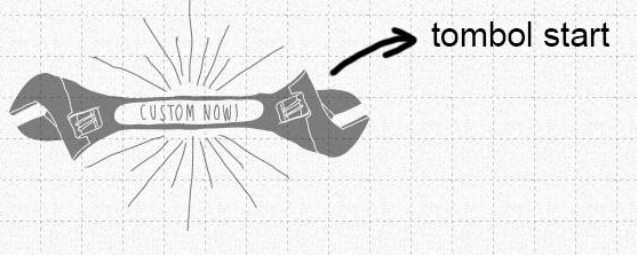

Gambar 14. Tombol Mulai. Sumber : (Maulana, 2014)

Halaman berikutnya adalah halaman dimana pengguna dapat memilih sepeda motor dasar apakah yang akan ia gunakan untuk merancang sepeda motor kustomnya. Pada halaman ini, pemilihan dirancang menggunakan halaman greybox. Halaman greybox adalah sejenis halaman yang dirancang agar pengguna dapat fokus terhadap informasi yang diberikan. Ciri 
utamanya adalah, layar belakang menjadi lebih gelap, tetapi masih dapat dilihat/transparan, Halaman muncul dengan efek halus (smooth pop-up effect). Pengguna dipersilahkan untuk memilih dengan mengklik gambar sepeda motor tersebut. Efek visual yang digunakan adalah carousel scroller. Sepeda motor akan berputar sesuai dengan arah dan posisi sepeda motor dasar yang dipilih.

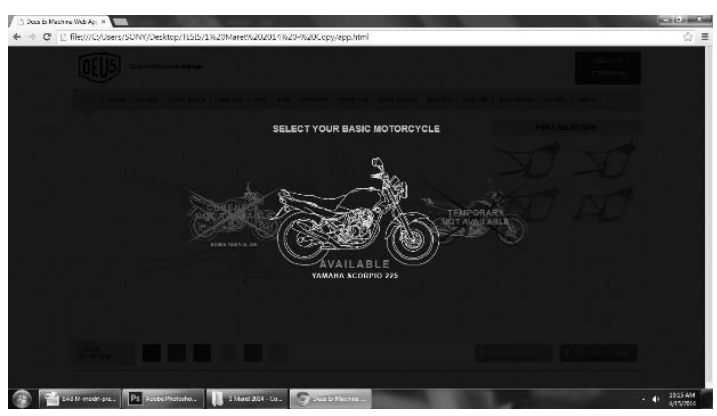

Gambar 15. Halaman seleksi sepeda motor dasar dalam bentuk greybox. Sumber : (Maulana, 2014)

Setelah pengguna memilih sepeda motor dasar mereka, dilanjutkan dengan halaman utama. Halaman ini terdiri dari topmenu, sidebarmenu, motorbike preview, colormenu, dan tombol media sosial. Bagian menu atas (topmenu), menu berbentuk horizontal dengan warna dasar kuning dan hitam sebagai warna tulisannya. Tombol menu atas, terdiri dari berbagai tombol bagian yaitu, frame/rangka, engine/mesin, exhaust/knalpot, front-shock/peredam kejut depan, hand grip/tuas gas, front lamp/lampu depan, air box/pelindung akumulator dan filter udara, front-rim/velg depan, front-tire/ ban depan, frontfender/spatbor depan, back-rim/velg belakang, back tire/ban belakang, back fender/ spatbor belakang, gastank/tanki bensin, saddle/jok.

Gambar 16. Tampilan menu atas / Topmenu. Sumber : (Maulana, 2014)
Menu samping/ Sidebarmenu adalah tempat munculnya opsi bagian parts yang dipilih pada menu atas. Apabila kita memilih menu frame pada menu atas, sidebarmenu akan menampilkan opsi apa saja yang dapat dipilih dari menu frame.

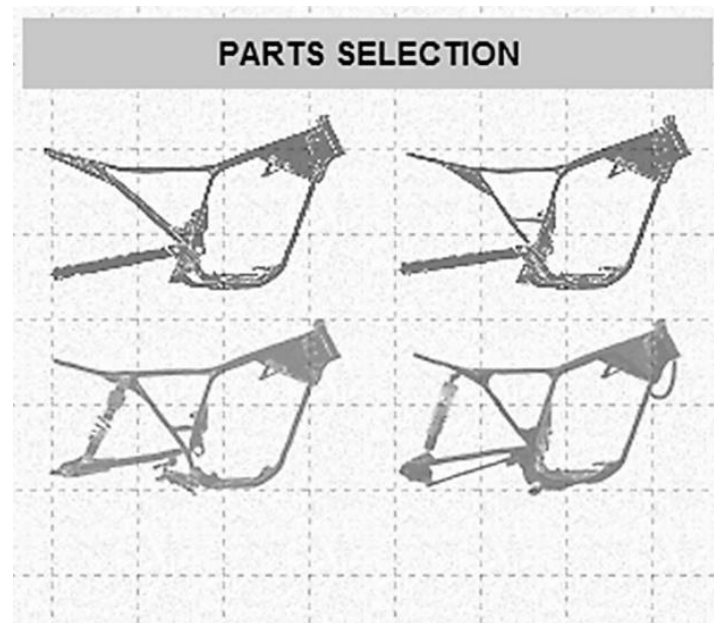

Gambar 17. Sidebarmenu/Menu sisi , menampilkan opsi dari jenis parts yang dipilih. Sumber : (Maulana, 2014)

Parts yang dipilih akan langsung muncul dibagian bike preview. Posisi bike preview ada dibagian kiri sejajar dengan sidebarmenu. Bagian ini terdiri dari berbagai macam parts yang posisinya sudah diatur menurut posisinya masing-masing, dengan bantuan bahasa pemrograman Javascript tampilan dan alur kerja dapat diatur sesuai dengan perintah yang dipilih pada menu atas dan menu samping. Javascript juga menyembunyikan parts yang tidak dipilih oleh pengguna.

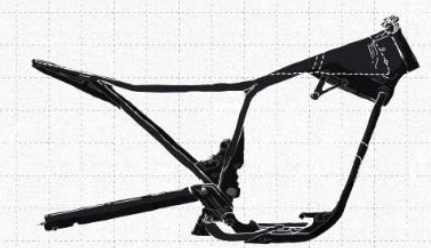

Gambar 18. Bike preview, tempat opsi parts ditampilkan. Sumber : (Maulana, 2014) 
Menu selanjutnya adalah colormenu, terletak dibagian bawah bike preview dan sidebarmenu. Pada menu ini pengguna dapat memilih warna sesuai dengan preferensi yang dikehendaki.

\section{con}

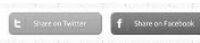

Gambar 19. Colormenu / menu warna dan tombol share media sosial. Sumber : (Maulana, 2014)

Pada menu ini warna pada palet warna disesuaikan dengan palet warna yang tersedia pada varian merek cat danagloss. Kombinasi warna yang ada menyesuaikan dengan ketersediaan bahan dan juga perhitungan perbedaan gradasi warna antara tampilan di monitor dan hasil aplikasi akhirnya. Sehingga penentuan palet dibuat dengan mencari kode warna dengan bantuan perangkat lunak Adobe Photoshop. Dengan menggunakan Eyedropper Tool, Sample warna diambil lalu didapatkan kodenya dan dipilih yang paling mendekati hasil akhir. Kode warna ini terdiri dari komposisi spesifik dari palet warna RGB dan Hexadecimal Triplet. Kode warna ini memiliki struktur sebagai berikut ; (\#RRGGBB). 'RR' terdiri dari kode warna Red, 'GG' Green, 'BB' Blue yang ditandai dengan angka, semakin tinggi angka semakin pekat pula warna yang dihasilkan. Angka yang digunakan adalah diantara 0255.

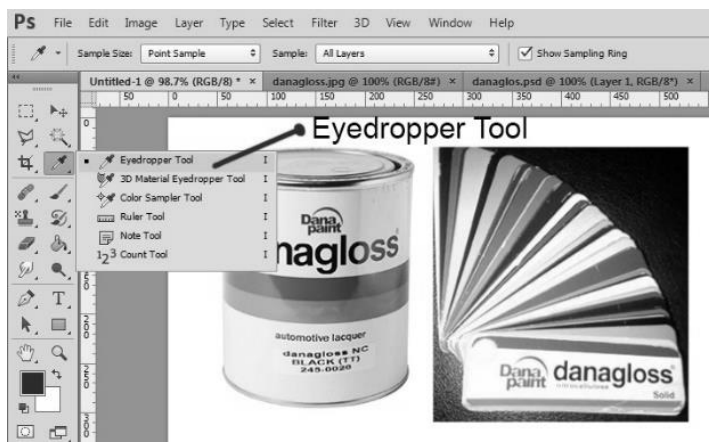

Gambar 20. warna diambil menggunakan Eyedropper Tool. Sumber : (Maulana, 2014)

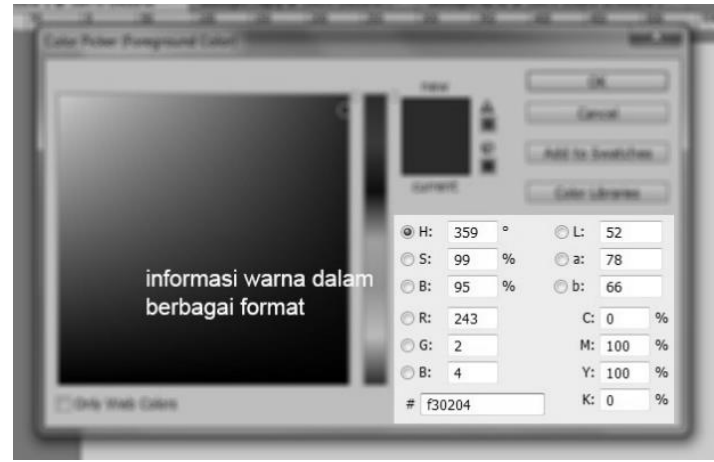

Gambar 21. Informasi warna dalam berbagai format. Sumber : (Maulana, 2014)

Pada situs web, digunakan informasi warna menurut palet RGB, sedangkan pada bahasa pemrograman, kode warna menggunakan hexadecimal triplet.

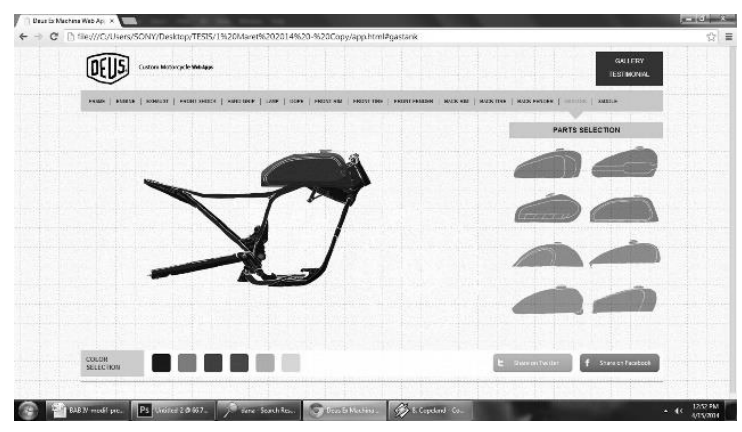

Gambar 22. Tampilan muka situs aplikasi versi desktop. Sumber : (Maulana, 2004)

\subsubsection{Tampilan versi Mobile Device}

Mobile device memiliki kelebihan mudah dibawa kemana saja karena ukurannya yang relatif kecil. Namun dari segi kemudahan merancang, versi desktop masih lebih unggul. Dengan begitu diperlukan beberapa penyesuaian agar versi mobile device memiliki tampilan muka yang optimal, salah satunya adalah dengan digunakan bahasa pemrograman HTML5, CSS3, dengan kode-kode khusus yang otomatis dapat merespon ukuran resolusi layar setiap device. Kode-kode ini dikenal dengan instilah Responsive CSS, ataupun dalam beberapa perangkat lunak disebut Responsive Themes. 


\subsubsection{Tampilan Versi Ponsel Pintar}

Terdapat banyak sekali merk dan jenis ponsel pintar yang beredar dipasaran. Setiap jenis memiliki spesifikasi yang berbeda-beda. Salah satu yang terpenting dalam perancangan situs aplikasi ini adalah resolusi layar. Berikut ini adalah perbedaan resolusi dari salaah satu merk ponsel pintar yang beredar di pasaran.
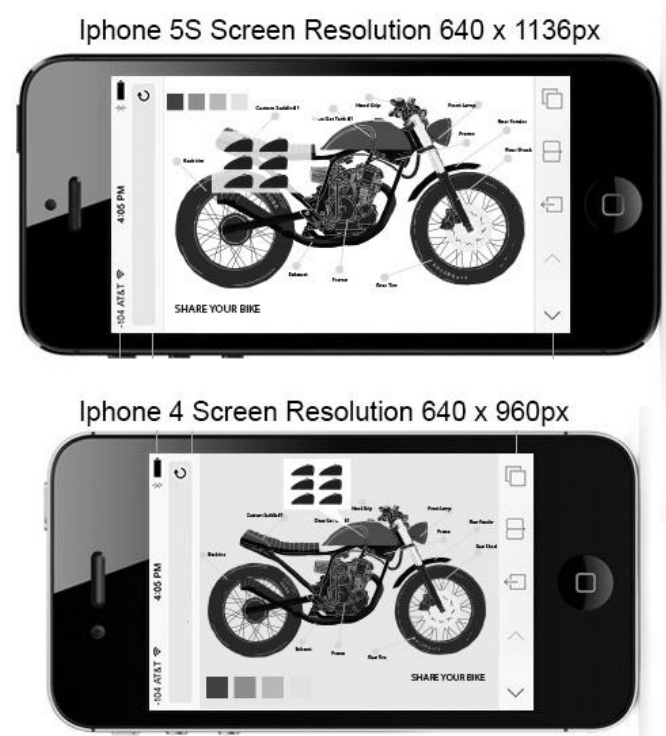

Gambar 23. Tampilan muka versi ponsel pintar. Sumber : (Maulana, 2014)

Perbedaan resolusi nanti dipikirkan, dikembangkan dan disesuaikan dengan jumlah pengguna terbanyak di kalangan target sasaran dari perancangan ini.

\subsubsection{Versi Tablet}

Tablet memiliki resolusi yang lebih besar dari ponsel pintar. Hal Ini tentu saja lebih mempermudah pengguna dalam merancang. Versi Tablet adalah versi yang sama dengan versi ponsel pintar. Perbedaannya hanya pada tampilan yang merespon ukuran resolusi layar.

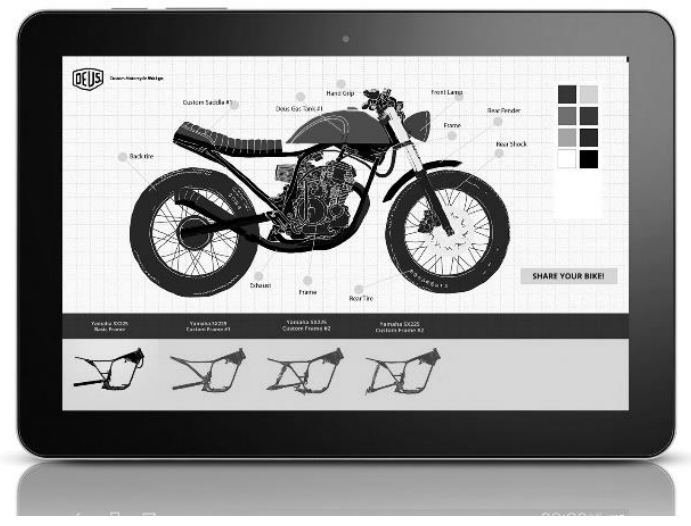

Gambar 24. Tampilan Muka pada Samsung Tab, dengan resolusi layar 1280 x 800px. Sumber : (Maulana, 2014)

\subsubsection{Respon Media Sosial}

\section{a). Facebook}

Media sosial facebook merupakan media sosial dengan pengguna terbanyak. Dengan trafik yang sangat tinggi, media ini menjadi favorit bagi perusahaan dan pengiklan dalam mempromosikan produk mereka. Dengan menekan tombol share pada situs aplikasi, Hasil rancangan akan otomatis muncul distatus pengguna. Dengan begitu, akan banyak orang melihat dan kemudian tertarik untuk mencoba situs aplikasi ini. Begitulah seterusnya pengguna lainnya akan mencoba dan membagikan hasil rancangan mereka di facebook.

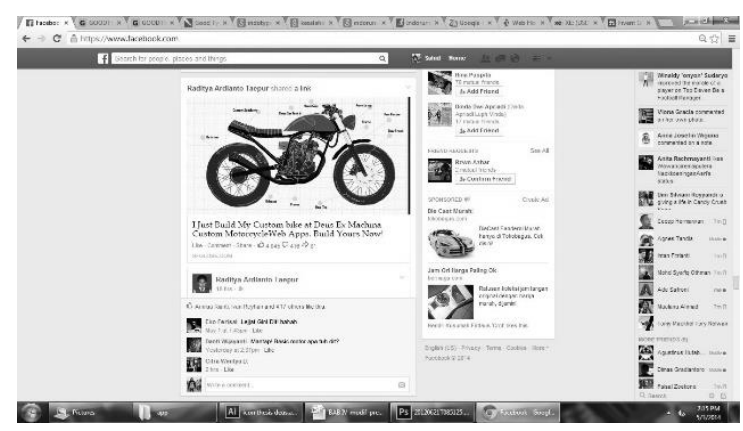

Gambar 25. Impresi Audiens dihalaman Facebook. Sumber (Maulana, 2014) 


\section{b). Twitter}

Twitter memiliki pola komunikasi yang berbeda dengan facebook, Twitter memiliki pola komunikasi yang sangat cepat dan rapat. Setiap Tweet memiliki keterbatasan pada karakter huruf yang ditulis, dan setiap tautan yang disertakan akan otomatis diperpendek agar pesan yang ditulis dapat lebih banyak. Dengan karakter seperti ini, dapat dipahami bahwa twitter adalah media komunikasi dengan range status update yang paling pendek dan rapat.

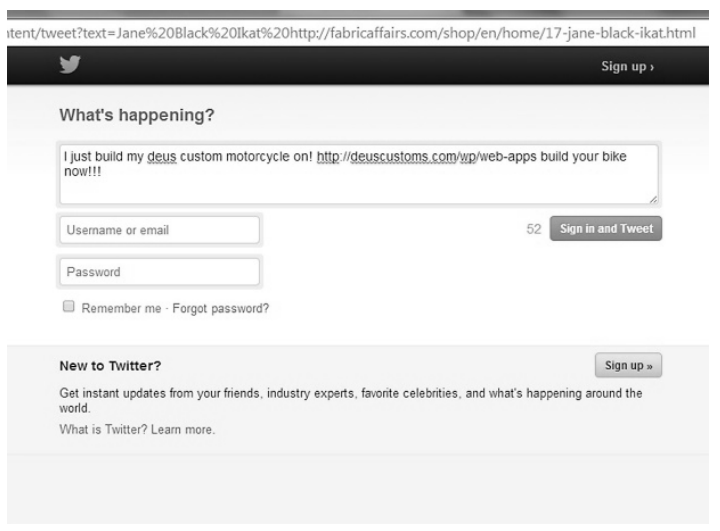

Gambar 26. Pop-up ketika pelanggan selesai merakit sepeda motor. Sumber (Maulana, 2014)

\section{KESIMPULAN DAN RINGKASAN}

\subsection{Kesimpulan}

Perancangan situs web aplikasi Deus Ex Machina ditujukan untuk memudahkan pelanggan dan builder sepeda motor kustom dalam merancang sepeda motor kustom. Keterbatasan pelanggan akan pengetahuan dan teknis pembuatan dan proses merancang terkadang menjadi faktor tidak sesuainya sepeda motor yang diinginkan. Namun terkadang kesalahan tafsir builder sepeda motor dan kekurangan referensi penunjang secara visual turut menjadi salah satu penyebabnya.
Setiap bengkel sepeda motor kustom memiliki pola kerja, pemahaman, dan teknik kerja yang berbeda satu dengan lainnya. Identitas ini menjadi karakter sebuah bengkel sepeda motor kustom, begitu juga dengan Deus Ex Machina. Karya yang dihasilkan memiliki karakter tertentu yang harus dipahami oleh juga oleh pelanggan.

Situs web kustomisasi yang dirancang memiliki tujuan mempolakan cara kerja bengkel dengan mendigitalisasi proses perancangan manual ke perancangan digital. Suku cadang yang digunakan oleh Deus Ex Machina, baik itu suku cadang pabrik, ataupun suku cadang yang dibuat khusus handmade dibuat mendekati presisi. Dengan fitur berbagi pada media sosial facebook dan twitter. Hasil rancangan sepeda motor yang sudah selesai dapat dibagikan di media sosial, dengan begitu orang lain akan melihat dan diharapkan tertarik dan mencobanya.

Perancangan situs aplikasi ini berakibat positif terhadap brand secara keseluruhan. Dengan platform aplikasi berbasis web, otomatis mendongkrak calon konsumen untuk mengakses situs resmi Deus Ex Machina. Dengan meningkatnya lalu lintas pengunjung, peluang terjualnya produk lain selain sepeda motor kustom akan meningkat juga.

\subsection{Saran}

Perancangan situs aplikasi sepeda motor kustom Deus Ex Machina ini sudah sampai tahap beta (beta version). Situs sudah dapat diakses secara online melalui penjelajah situs (web browser). Meskipun begitu fitur-fitur tertentu masih perlu dikembangkan. Hal ini berkaitan dengan terbatasnya modal yang diperlukan untuk merampungkan rancangan. 
Perancangan membutuhkan dua basis pemrograman, basic HTML5, CSS3 yang didukung dengan Javascript. Versi ponsel pintar dan tab belum dikembangkan secara maksimal, tampilan muka web haruslah responsif, dalam artian tampilan muka web harus bisa menyesuaikan secara otomatis dengan perangkat yang digunakan konsumen. Tahap uji coba aplikasi cukup memakan waktu dan biaya yang tidak sedikit.

Situs aplikasi sebaiknya diuji coba oleh beberapa calon pelanggan potensial sehingga mampu memberikan umpan balik yang optimal. Pengumpulan gambar suku cadang, terlebih lagi yang dibuat kustom, harus sangat presisi antara gambar, spesifikasi parts, dan informasi yang ditampilkan pada halaman situs.

Dalam proses perancangan situs aplikasi ini banyak sekali masukan yang didapat dari rekan-rekan yang menaruh perhatian pada sepeda motor kustom. Beberapa saran tersebut saat ini masih dalam proses penampungan untuk tahap pengembangan selanjutnya. Saran tersebut paling banyak diantaranya adalah menampilkan berbagai tampak dari sepeda motor, namun sampai saat ini masih dalam tahap masukan saja.

\section{DAFTAR PUSTAKA}

[1] Marije L. Teerling dan Eelko K.R.E. Huizingh, 2006, Exploring the Concept of Web Site Customization: Applications and Antecedent, Netherlands.

[2] Horst Treiblmaier, Maria Madlberger, Nicolas Knotzer, Irene Pollach, 2004, Evaluating Personalization and Customization from an Ethical Point of View: An Empirical Study, Austria.

[3] Kartajaya, Hermawan, 2010, New Wave Marketing: The World is Still Round The Market is Already Flat, PT. Gramedia Pustaka Utama, Jakarta.

[4] Gobe, 2005, Emotional Branding: paradigma baru untuk menghubungkan merek dengan pelanggan, Penerbit Erlangga: Jakarta.

[5] Andi Taru Nugroho NW, 2012, Pemrograman Game Berbasis Web Menggunakan JavaScript + HTML 5, Andi Publisher: Jakarta.

[6] M. Shalahuddin \& Rosa A.S., 2007, Belajar Pemrograman dengan Bahasa Pemrograman $\mathrm{C}++$ dan Java, Penerbit Informatika: Jakarta. 